\title{
Performance Assessment of a Batch Distillation System
}

\author{
S.O. Mert ${ }^{*}$, E. Ersöz ${ }^{2}$, M.U. Badak ${ }^{1}$ \\ ${ }^{1}$ Yuzuncu Y1l University, Department of Chemical Engineering, 65080, Van, Turkey \\ ${ }^{2}$ Ege University, Department of Chemical Engineering, 35100, Bornova, İzmir, Turkey
}

Received 19 February 2015, Revised 19 April 2015, Accepted 23 April 2015

\begin{abstract}
In this study, the performance analysis of a batch distillation system, which is being used to recover ethylene glycol from the waste products of a chemical plant, was conducted using the exergy analysis method. The analysis is thorough and detailed, including a broad modelling of the system and a comprehensive "reference temperature" investigation. The aforementioned waste solution contains water, glycols, and some anhydrides. The purification process of this waste is sustained using a distillation system that operates in a batched manner and is heated using an electric heating system. In this study, the heating system, reboiler, and condenser groups of the distiller are investigated to better understand the characteristics of the system and to reveal the efficiencies "exergetically". Overall, with data from the real-case and data gathered from the experiments, the system's exergetic efficiencies are calculated, over time, during the distillation process. This way, the major exergy destruction points for the system are pointed out, in hopes of reaching better efficiency and reduced costs for the system. The effect of the environmental temperature is also investigated with the utilized exergetic model. As a result of the investigation, the overall efficiency for the distillation system was found to be $3.41 \%$ and the overall exergy destruction as $282.13 \mathrm{~kW}$.
\end{abstract}

Keywords: Exergy; batch distillation; separation; ethylene glycol; performance investigation.

\section{Introduction}

Distillation is an energy intensive process and most of the earlier studies concentrate on the "optimum reflux ratio" and "column pressure" with the idea of increasing column efficiency [1-2]. But nowadays, the reduction of energy consumption in the distillation processes has become a more important, due to limited energy sources and increasing energy demands [3-6]. Energy consumption of the distillation processes can be reduced by minimizing either "the energy dissipation" or "work lost". For these reasons, in such studies the terms exergy and by natural extension "exergy analysis" came into prominence [7].

Exergy can be defined as the "maximum useful work". Exergy analysis may lead to a better efficiency and sustainable use of energy, at a given state and in a given environment. For this reason, the method is widely used in the engineering and multi-disciplined working fields over the last several decades $[10,11]$. It is a tool of the second law of thermodynamics, which lets us find and focus on the sources of energy losses of a thermal system. In the exergy analysis, the difference between the "quality" and "quantity" of the energy is emphasized, and by applying this method, more efficient operating conditions for any given thermodynamic system can be investigated [10]. This also means that by utilization of exergy analysis, distillation columns can be analysed thermodynamically, to compute the "net energy gained" and deduce the source and amount of losses during operation. Along with this, exergy analysis lets us analyse the effect of environmental parameters on the system as well. With the inclusion of the effects of the environment on the system in this study, the hope is to theoretically achieve the true characteristic and capacity of the thermal system in detail [11]. As mentioned before, exergy analysis is also used as a tool to identify the types, locations, and magnitudes of the sources of energy losses in a given system. It is crucial to identify and quantify these losses for the betterment of system efficiencies and sustainable productions [12].

In literature, there are some studies on the evaluation of distillation systems, which seek energy and exergy efficiency and exergy flows through the system [13-14]. They report that the exergy efficiency to be $4.2 \%$ in a multi-stage flash distillation plant. In these studies, a crude oil refinery column and an adiabatic-diabatic experimental water/ethanol rectifying column were investigated. These studies show that a diabatic column is more efficient than an adiabatic variant by a $33.5 \%$ margin [15]. Some of the studies have determine the exergetic flows as well [16]. Researchers have also used computerized methods in order to increase the exergy efficiency of the distillation systems, and found that it is possible to decrease exergy losses from $12 \%$ to $21 \%$ [17]. Furthermore, there are some techniques to reduce the exergy loss in distillation columns by using "a three dimensional exergy analysis curves". Investigations of the effects of the environment conditions show that as the environmental temperature increases, overall column efficiency decreases [18]. Also, modelling, integration, and optimization are prevailing subjects on which research about batch distillation focus [19-22] in literature.

This study aims to apply exergy analysis to a real-case system that recovers ethylene glycol from a feed of waste stream solution from a chemical plant in a batch distillation column. The feed to be distilled contains mainly ethylene glycol $\left(\mathrm{C}_{2} \mathrm{H}_{6} \mathrm{O}_{2}\right)$, propylene glycol $\left(\mathrm{C}_{3} \mathrm{H}_{8} \mathrm{O}_{2}\right)$, and water $\left(\mathrm{H}_{2} \mathrm{O}\right)$ along with some other chemicals at insignificant levels. 


\section{Exergy Analysis}

Exergy analysis depends on the second law of thermodynamics as it takes entropy into consideration. Exergy can be destroyed so it is a non-conserved property. To calculate a system's exergy, surroundings and the system must both be defined. Surroundings are defined as the "reference environment" and all the exergy calculations are done depending on these environmental conditions. Temperature, pressure, and composition of the reference environment are specified and assumed to be constant. The reference environment may be the atmosphere, earth crust, or the ocean. The reference environment may also be thought of as a thermal reservoir [12].

There exist various components of exergy. Depending on the system's definition and characteristics, some of these components may be excluded from the investigation and calculations. These components are physical, kinetic, chemical, potential, nuclear, magnetic, electrical, and surface tension forms of exergy. In this study, only physical and chemical exergies of the streams are taken into account, considering the relatively low contributions of the others.

$$
E x=E x_{p h y}+E x_{c h}
$$

The physical exergy is the result of the transformation of the system's conditions to the "reference states", which are defined by P0 and T0, through the physical processes, and only involving thermal interaction with the environment,

$$
\begin{aligned}
& E x_{p h y}=\left(U-U_{o}\right)+P_{0}\left(V-V_{0}\right)-T_{0}\left(S-S_{0}\right) \\
& E x_{p h y}=\left(H-H_{0}\right)-T_{0}\left(S-S_{0}\right)
\end{aligned}
$$

where 0 refers for the reference environment.

The chemical exergy of a stream is the sum of the substances' calorific value. It is defined as the energy results caused by the difference in the substance composition with respect to the common components of this substance in the environment [23]. Chemical exergy is evaluated by bringing the pure component to a chemical equilibrium with the environment. This means the departure of the chemical composition of the material from the "reference condition" increases the chemical exergy of it [24].

The chemical exergy of a pure substance is calculated with respect to their reference environments

$$
E x_{c h}=\Delta G-\sum_{i=1}^{N} v_{i} E x_{0, c h, i}
$$

where $\Delta G$ denotes the change in the Gibbs energy of formation, $v$ denotes the stoichiometric coefficient, and $E x_{0, \text { ch, } i}$ denotes the standard chemical exergy of the substance.

By using the standard chemical exergy values [25] gathered from the literature, the chemical exergies multicomponent mixtures are calculated as follows

$$
E x_{c h, m i x}=\sum_{i=1}^{N} x_{i} E x_{c h, i}+R T_{0} \sum_{i=1}^{N} x_{i} \ln x_{i}
$$

where $\mathrm{x}$ is the mole fraction of the substance.

\section{System Description}

The investigated system is composed of two stages. Studies are carried out in both "laboratory scale" and "pilot scale" batch distillation setup. The distillation operation is initially studied in the laboratory, to better survey true system characteristics of the separation operation. Then, with the gathered knowledge of the experimental study and the theoretical investigation, a pilot operation is applied in a realuse case, with a batch distillation system.

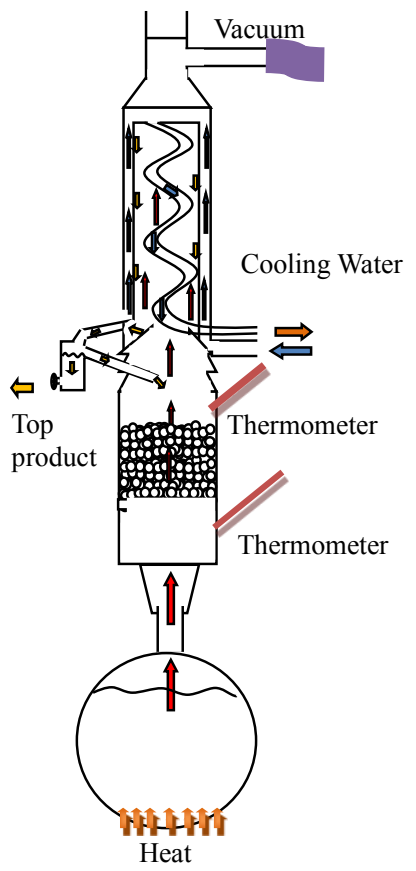

Figure 1. The scheme of the experimental setup.

The experimental studies are carried out on an electrically heated flask which is connected to a glass column filled with rasching rings of $1 \mathrm{~cm}$ size, which is used for distillation. The length of the column is $1.3 \mathrm{~m}$, and a cooler condenser group is mounted at the top of the column as shown in Figure 1. The system is operated in a batch manner, to replicate the pilot system, and the temperature profiles and components' fractions in the processes are observed with respect to time. The samples are taken both from the distillate and the bottom product at pre-determined time intervals.

After the laboratory scale experimental study, the necessary data is gathered and the process is carried out on the pilot size setup. The scheme of the system investigated for the exergy analysis is given in Figure 4. The pilot size distillation process consists of a Rasching ring filled glass column, insulated boiler, and a condenser as seen in Figure 2. The height of the column is $6.7 \mathrm{~m}$ and the height of the packing material is $5 \mathrm{~m}$. The distillation system can be operated in batch and continuous modes, each with/without reflux. In this study, the batch distillation was investigated. The required heat for the process is provided by a hot oil system, which is heated with an electric heater. The heater has 18 resistance cells to heat the oil and each requires $6 \mathrm{~kW}$ energy (Figure 3).

The mixture to be recovered is composed of glycols and water with trace amount of anhydrides (Table 1). The feed solution is a waste product of a chemical plant. Since various chemical production processes use relatively high amounts of glycols in large-scale heat transfer fluid applications, 
recovery of the glycol in such waste products becomes profitable and environmentally friendly proves.

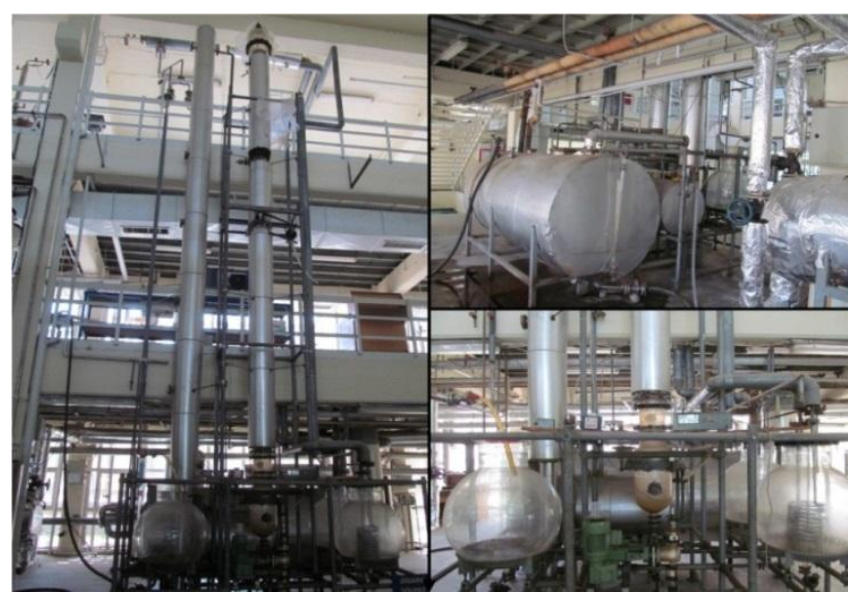

Figure 2. Pilot size distillation column.

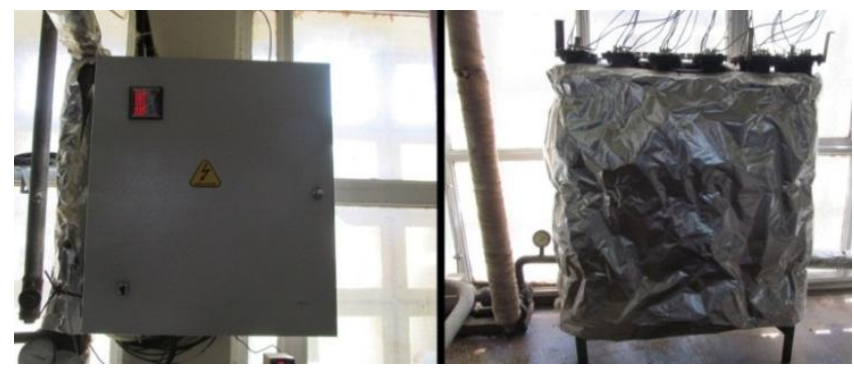

Figure 3. Electrical heater and its control panel.

Table 1. The Weight Fractions and Physical Properties of the Components in the Waste Solution [25,26].

\begin{tabular}{crrrr}
\hline Component & $\begin{array}{r}\text { Weight } \\
\text { Percent } \\
{[\%]}\end{array}$ & $\begin{array}{r}\text { Molecular } \\
\text { Weight } \\
{[\mathrm{kg} / \mathrm{kmol}]}\end{array}$ & $\begin{array}{r}\text { Boiling } \\
\text { Point } \\
{\left[{ }^{\circ} \mathrm{C}\right]}\end{array}$ & $\begin{array}{r}\text { Standard } \\
\text { Ehemical } \\
\text { Exergy } \\
{[\mathrm{kJ} / \mathrm{kmol}]}\end{array}$ \\
\hline $\begin{array}{c}\text { Ethylene } \\
\text { glycol }\end{array}$ & 18.0 & 62.08 & 197.3 & 1214.2 \\
$\begin{array}{c}\text { Propylene } \\
\text { glycol }\end{array}$ & 61.0 & 60.11 & 188.2 & 2007.8 \\
$\begin{array}{l}\text { Water } \\
\text { other }\end{array}$ & $\begin{array}{r}20.0 \\
1.0\end{array}$ & 18.00 & 100.0 & 1.3 \\
\hline
\end{tabular}

\section{Exergy Analysis of Batch Distillation System}

The batch distillation system process that was subject to exergy calculations is shown in Figure 4. In this study, each stream's exergy is calculated with respect to the time interval of the distillation process, and exergetic efficiencies and the exergy destruction is calculated according to the exergy balance

$\mathrm{Ex}_{\mathrm{dest}}=\mathrm{Ex}_{\mathrm{in}}-\mathrm{Ex}_{\mathrm{out}}-\mathrm{Ex}_{\mathrm{loss}}$

The components in the feed and energy fed to the reboiler is taken as input exergies and the distillate is taken as output exergy. The system is well insulated, yet in the calculations, $5 \%$ of the heat supplied to the system is assumed to be lost through the pipes and equipment.

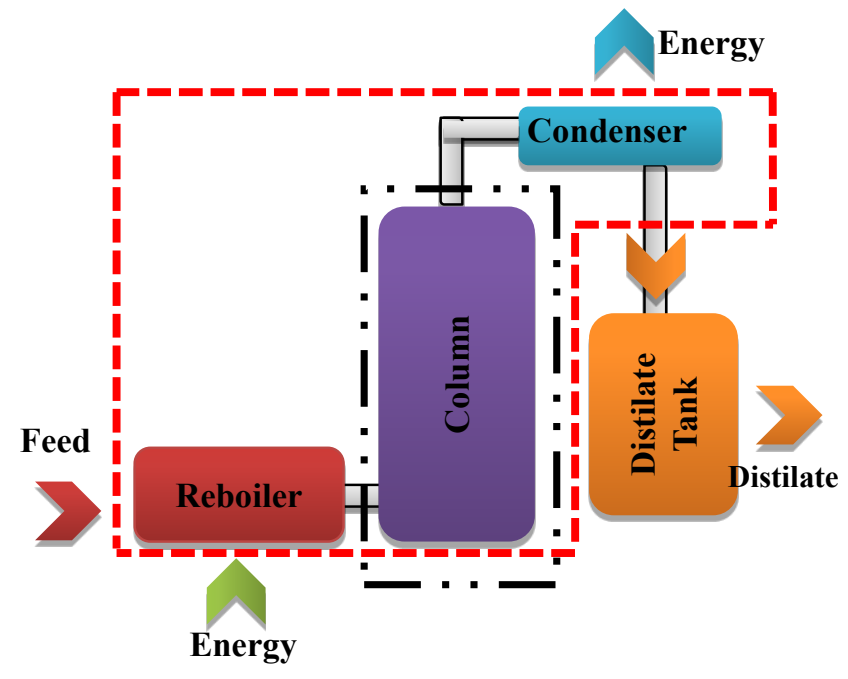

Figure 4. Exergy analysis scheme.

The second-law based exergy efficiency of a process may be defined as "exergy recovered (exergy output) relative to the exergy input". Exergy output can be defined as the product of the system or, in other words, "useful exergy output" [27]. In this study, since the product is the distillate, the exergy of the distillate relative to the exergy input by the reboiler heating system is taken in to account, with respect to the determined time intervals

$\eta=\frac{E x_{\text {out }}}{E x_{\text {in }}}$

\section{Results and Discussion}

During the separation process, more volatile components (MVC) are evaporated rapidly in the early stages of the batch distillation operation, as a result, the less volatile components' (LVC) fractions in the distillate is increased. According to this principle, water is removed from the system during this initial evaporation and the remaining mixture becomes richer in glycol content. On the other hand, because of the presence of various polymer residuals and other chemicals, as this mixture is further distilled, most of the glycol components are taken from the top of the columns as distillate and the remaining residuals became a rather dense chemical waste.

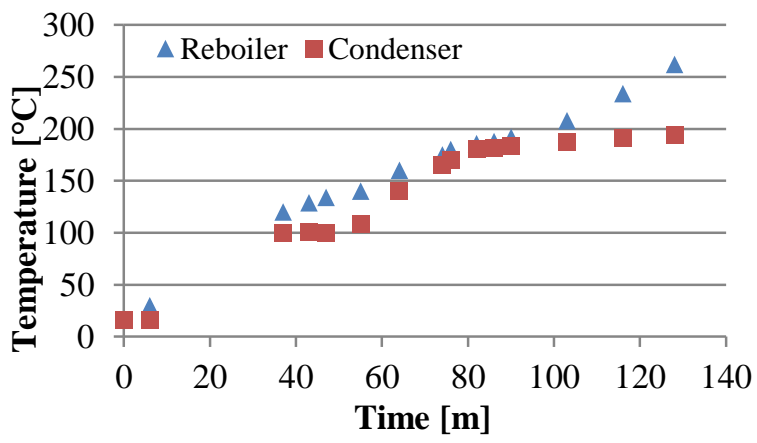

Figure 5. The temperature profile for the system.

Since the fractions of the components, both in the tank and in distillate are changing over time, the temperatures are also changing in both the condenser and the reboiler (Figure 
5). This change is based on the "bubble point" and "dew point" of the mixtures. The temperatures are measured with glass thermometers, which are placed post-reboiler and precondenser as shown in Figure 1-a. As the fraction of more volatile components decreases in the tank, the temperatures increase for both the condenser and the reboiler, since its boiling point is relatively low at this stage.

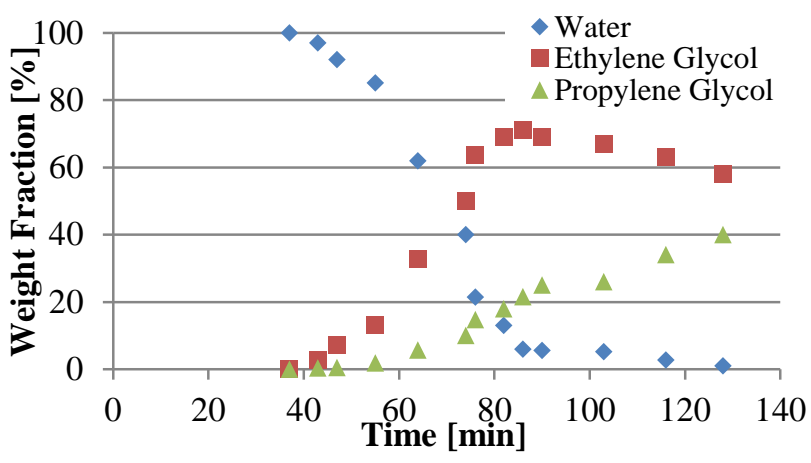

Figure 6. The components present in the distillate during the distillation process.

The components' mass fraction in the distillate during the distillation operation time is given in Figure 6. These are determined by gas chromatography (GC) analysis, with the samples taken through the distillation process at predetermined time intervals. As can be seen from the figure, the fraction of the more volatile component (MVC) that is water decreases, while the other components' fractions increase as the temperature increases and time passes. This is a result of an increase of the composition of glycols in the vapour phase as the distillate. The residue of the distillation process is kept in the reboiler tank and the relevant composition trends are shown in Figure 7.

The results for the exergy analysis of the batch distillation operation is tabulated and presented in graphs with respect to the time passed in the operation. For every step of the time increment, the evaporated amount of mixture is calculated, and depending on the energy input regarding to the system operation, the exergy balance is applied. Table 2 shows the values for exergies, and efficiencies with respect to the time spent in the distillation operation.

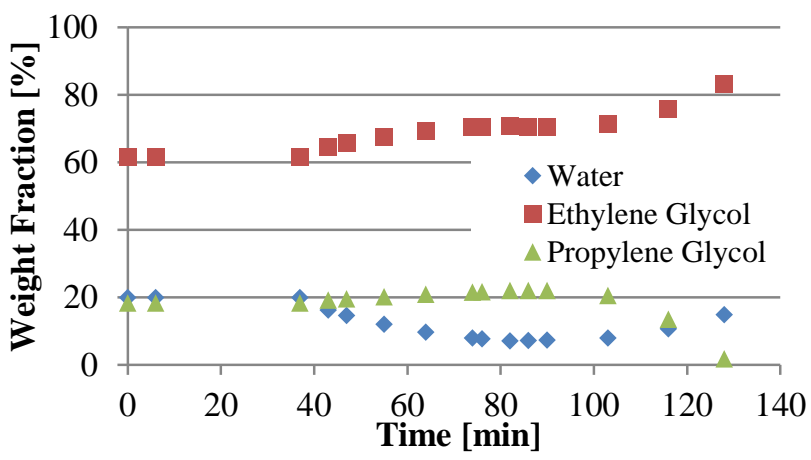

Figure 7. The components present in the reboiler tank during the distillation process.
Table 2. Exergy Values in the Separation Operation.

\begin{tabular}{rrrrr}
\hline $\begin{array}{r}\text { Time } \\
{[\mathrm{m}]}\end{array}$ & $\begin{array}{r}\text { Energy } \\
\text { Input } \\
{[\mathrm{kW}]}\end{array}$ & $\begin{array}{r}\text { Tank Exergy } \\
{[\mathrm{kW}]}\end{array}$ & $\begin{array}{r}\text { Distillate } \\
\text { Exergy }[\mathrm{kW}]\end{array}$ & $\begin{array}{r}\text { Efficiency } \\
{[\%]}\end{array}$ \\
\hline 0 & 16.42 & 27.32 & 0.00 & 0.00 \\
6 & 14.43 & 27.29 & 0.00 & 0.00 \\
37 & 5.55 & 27.07 & 0.00 & 0.00 \\
43 & 12.84 & 27.01 & 0.06 & 0.47 \\
47 & 11.22 & 26.95 & 0.14 & 0.72 \\
55 & 10.03 & 26.79 & 0.29 & 1.52 \\
64 & 13.56 & 26.26 & 0.77 & 3.68 \\
74 & 13.63 & 25.32 & 1.32 & 4.33 \\
76 & 18.01 & 24.97 & 1.68 & 2.04 \\
82 & 15.02 & 22.84 & 2.43 & 5.82 \\
86 & 24.37 & 21.06 & 3.08 & 2.88 \\
90 & 27.79 & 20.52 & 3.25 & 0.62 \\
103 & 28.70 & 15.12 & 5.36 & 9.06 \\
116 & 25.22 & 09.25 & 8.09 & 14.11 \\
128 & 33.56 & 05.58 & 9.97 & 6.29 \\
\hline
\end{tabular}

Figure 8 shows the variation of the exergies of tank and distillate with respect to the time, as well as the exergy efficiency. Here it can be perceived that as the time passes, the exergy in the tank decreases as expected, since at that point, as some portion of the mixture is evaporated, exergy is transferred via mass transfer. Yet still, it is clear from these results that a large portion of the exergy cannot be utilized due to the exergy destruction.

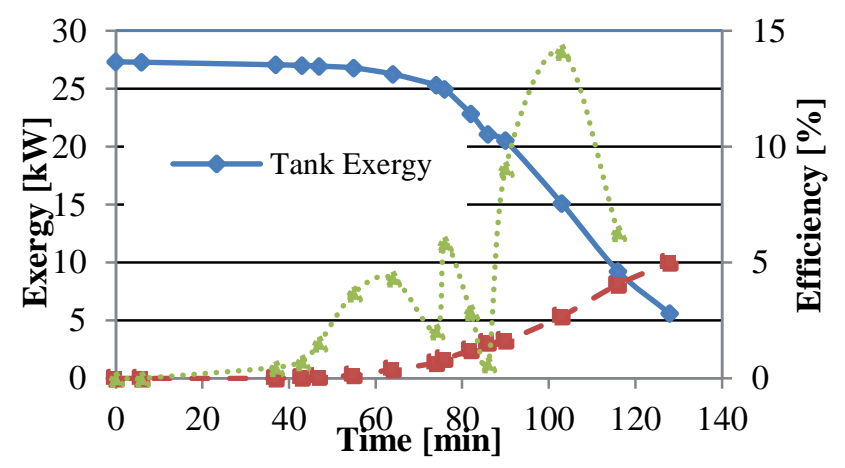

Figure 8. The variation of the exergies and efficiencies in the separation operation.

The results of exergy efficiency shows that, most of the exergy destruction occurs around the reboiler. Figure 9 shows the values of exergy destruction and exergy losses. The heat losses to the surroundings increase, since the temperature and heat load to the system increase as the reboiler temperature increases. On the other hand, the destruction of exergy in the system also has a similar tendency, except at the start-up of the operation where a larger amount of destruction occurs. This is also expected because of the high temperature difference between the heating medium and the tank content at that point in time.

In Table 3 the overall results for the operation is calculated and tabulated. These values are the representation of the total energy input to the system in the form of electricity and exergy by mass. The cumulative energy input, mass input and outputs are calculated with respect to time intervals and used in the total exergy balance calculations for revealing the total exergy efficiency and exergy destruction. It is seen that the efficiency is around $3 \%$ which is 
considerably low for a thermal system. These rather extreme values emphasize the benefits of proper insulation and usage of electricity instead of fuel oil, coal, or natural gas in systems that include a combustion process.

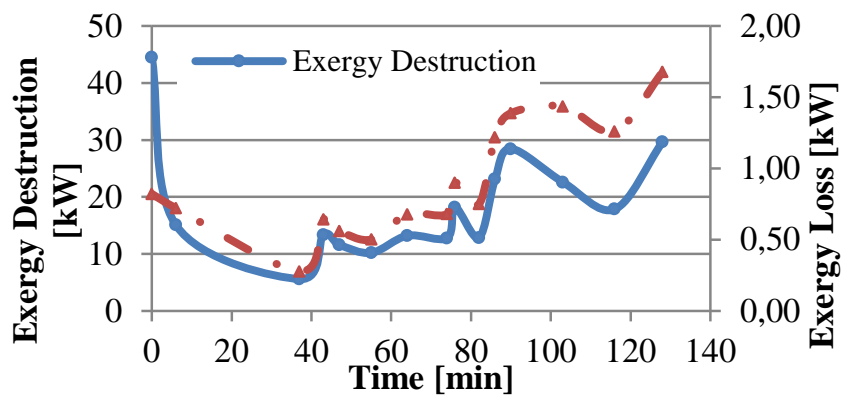

Figure 9. The variation of the exergy destruction and loss.

Table 3. The Overall Results for the System.

Total Exergy Destruction Total Exergy Efficiency $[\mathrm{kW}]$ [\%]

282.13

3.41

In Figure 10 the investigation of the reference temperature through exergetic modeling on the systems exergetic performance is illustrated. Results show that, as the environmental temperature increases, the exergetic efficiency of the system also increases. The system also shows a similar tendency with respect to the change in reference temperature.

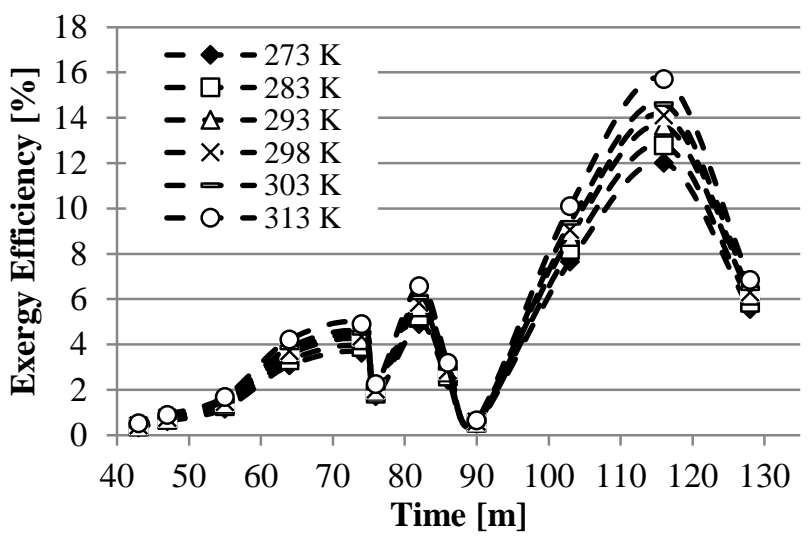

Figure 10. Parametric investigation of reference temperature on exergy efficiency.

\section{Conclusion}

In this study the exergy analysis of a batch distillation operation with a mixture of water and glycol compounds was investigated. The investigation is based on samples collected at pre-determined time intervals, and the exergy values of the distillate and the residuals in the tank are calculated, along with the efficiencies and overall exergy destruction of the system.

It is seen that the efficiency values are higher in the early steps of the operation where the temperatures are low compared to the later stages of operation where the temperatures reach $560 \mathrm{~K}$.

The overall efficiency was found as $3.41 \%$ and the overall exergy destruction as $282.13 \mathrm{~kW}$. The destruction of exergy mostly arises in the reboiler section of the system, where the heat transfer and evaporation processes take place. Following the reboiler, the other important point of exergy destruction is the condenser, where the distillate condenses.

This shows us there is a large space for energy conservation betterment in the studied process, and any increment in the efficiency of the heat transfer will greatly contribute to the total efficiency and thus reduce the cost of the operation.

After such an exergetic analysis, the application of an exergoeconomic analysis and an optimization study will further increase the depth of the investigation of this system.

\begin{tabular}{ll}
\multicolumn{2}{l}{ Nomenclature } \\
$E x$ & Exergy, $[\mathrm{kW}]$ \\
$U$ & Internal energy $[\mathrm{kJ}]$ \\
$P$ & Pressure $[\mathrm{atm}]$ \\
$V$ & Volume $\left[\mathrm{m}^{3}\right]$ \\
$S$ & Entropy $[\mathrm{J} / \mathrm{K}]$ \\
$T$ & Temperature $[\mathrm{K}]$ \\
$H$ & Enthalpy $[\mathrm{kJ}]$ \\
$R$ & Universal gas constant $[\mathrm{J} / \mathrm{molK}]$ \\
$G$ & Gibbs free energy of formation $[\mathrm{kJ} / \mathrm{mol}]$ \\
$x$ & Mole fraction $[-]$
\end{tabular}

\section{Greek Letters}

$\eta$

Efficiency [-]
Stoichiometric coefficient [-]

$\begin{array}{ll}\text { Subscripts } & \\ \text { dest } & \text { Destruction } \\ \text { in } & \text { Input } \\ \text { out } & \text { Output } \\ \text { loss } & \text { Loss } \\ \text { phy } & \text { Physical } \\ \text { ch } & \text { Chemical } \\ 0 & \text { Reference state }\end{array}$

\section{References}

[1] A. T. Sundberg, P. Uusi-Kyyny, K. Jakobsson, and V. Alopaeus, "Control of reflux and reboil flow rates for milli and micro distillation," Chem. Eng. Res. Des., vol. 91, pp. 753-760, 2013.

[2] D. Barbosa and M. F. Doherty, "Design and minimum-reflux calculations for single-feed multicomponent reactive distillation columns," Chemical Engineering Science, vol. 43. pp. 15231537, 1988.

[3] V. R. Dhole and B. Linnhoff, "Distillation column targets," Computers \& Chemical Engineering, vol. 17. pp. 549-560, 1993.

[4] I. J. Halvorsen and S. Skogestad, "Energy efficient distillation," J. Nat. Gas Sci. Eng., vol. 3, pp. 571-580, 2011.

[5] G. Soave and J. A. Feliu, "Saving energy in distillation towers by feed splitting," in Applied Thermal Engineering, vol. 22, pp. 889-896, 2002.

[6] A. A. Kiss, S. J. Flores Landaeta, and C. A. Infante Ferreira, "Towards energy efficient distillation technologies - Making the right choice," Energy, vol. 47, pp. 531-542, 2012. 
[7] Y. Demirel, "Thermodynamic Analysis of Separation Systems," Separation Sci. Technol., vol. 39. pp. 3897 3942, 2004.

[8] G. D. Vučković, M. M. Stojiljković, M. V. Vukić, G. M. Stefanović, and E. M. Dedeić, "Advanced exergy analysis and exergoeconomic performance evaluation of thermal processes in an existing industrial plant," Energy Convers. Manag., Apr. 2014.

[9] S. O. Mert, I. Dincer, and Z. Ozcelik, "Performance investigation of a transportation PEM fuel cell system," Int. J. Hydrogen Energy, vol. 37, no. 1, pp. 623-633, 2012.

[10] I. Dincer, "The role of exergy in energy policy making," Energy Policy, vol. 30, pp. 137-149, 2002.

[11] I. Dincer and M. A. Rosen, "Exergy, environment and sustainable development," in EXERGY, 2007, pp. 3659.

[12] I. Dincer and M. A. Rosen, Exergy: energy, environment and sustainable development, vol. 64. Newnes, 2012.

[13] H. Baig, M. A. Antar, and S. M. Zubair, "Performance evaluation of a once-through multi-stage flash distillation system: Impact of brine heater fouling," Energy Convers. Manag., vol. 52, no. 2, pp. 1414 1425, Feb. 2011.

[14] A. Ficarella and D. Laforgia, "Energy conservation in alcohol distillery with the application of pinch technology," Energy Convers. Manag., vol. 40, no. 14, pp. 1495-1514, Sep. 1999.

[15] G. de Koeijer and R. Rivero, "Entropy production and exergy loss in experimental distillation columns," Chem. Eng. Sci., vol. 58, pp. 1587-1597, 2003.

[16] R. Rivero, C. Rendón, and S. Gallegos, "Exergy and exergoeconomic analysis of a crude oil combined distillation unit," Energy, vol. 29, no. 12, pp. 19091927, 2004.
[17] M. S. Olakunle, Z. Oluyemi, A. S. Olawale, and S. S. Adefila, "Distillation Operation Modification with Exergy Analysis," J. Emerg. Trends Eng. Appl. Sci., vol. 2, pp. 56-63, 2011.

[18] H. Al-Muslim, I. Dincer, and S. M. Zubair, "Effect of reference state on exergy efficiencies of one- and twostage crude oil distillation plants," Int. J. Therm. Sci., vol. 44, pp. 65-73, 2005.

[19] G. Modla and P. Lang, "Heat pump systems with mechanical compression for batch distillation," Energy, vol. 62, pp. 403-417, 2013.

[20] M. Hanke and P. Li, "Simulated annealing for the optimization of batch distillation processes," Comput. Chem. Eng., vol. 24, pp. 1-8, 2000.

[21] I. M. Mujtaba and S. Macchietto, "Efficient Optimization of Batch Distillation with Chemical Reaction Using Polynomial Curve Fitting Techniques," Ind. Eng. Chem. Res., vol. 36, pp. 2287-2295, 1997.

[22] L. S. Balasubramhanya and F. J. Doyle Iii, "Nonlinear model-based control of a batch reactive distillation column," J. Process Control, vol. 10, pp. 209-218, 2000.

[23] J. G. Speight, "A Review of: 'The Exergy Method: Technical and Ecological Applications," Energy Sources, vol. 27. pp. 1099-1101, 2005.

[24] I. Dincer and Y. A. Cengel, "Energy, Entropy and Exergy Concepts and Their Roles in Thermal Engineering," Entropy, vol. 3. pp. 116-149, 2001.

[25] T. J. Kotas, "Exergy Concepts for Thermal Plants," International Journal of Heat and Fluid Flow, vol. 2. pp. 105-114, 1980.

[26] R. H. Perry and D. W. Green, Perry's Chemical Engineers' Handbook. 2008.

[27] S. O. Mert, Z. Özçelik, Y. Özçelik, and I. Dinçer, "Multi-objective optimization of a vehicular PEM fuel cell system," Appl. Therm. Eng., vol. 31, no. 13, pp. 2171-2176, 2011. 